\title{
OBLIGATIONAL RELATIONS IN THE MIDST OF DIGITALIZATION OF BUSINESS ACTIVITY: THE CONCEPT AND TYPES
}

\author{
Nizami Elmar oglu Safarli \\ Volgograd State University, Volgograd, Russian Federation
}

\begin{abstract}
Introduction: civil obligations are one of the central institutions of the civil law system, which is currently undergoing a new stage of understanding and development. The domestic civil law quite clearly identified the tasks that are urgent for theoretical, as well as comparative and practical research aimed at analyzing the problems of obligations that arise from civil law and business contracts. Purpose: to analyze the features of the regulation of market relations at the contractual level in the midst of digitalization of business activity. Methods: the methods of systematicity, analysis, and comparative law are used in the work. Results: the legal regulation ensures the implementation of equality as one of the most important principles of civil law: by setting additional requirements for entrepreneurs, the state equalized them with other participants in the turnover. This also dictates the need for the active introduction and application of legal means as proactive actions based on the permissibility of the law. One of them is a contract, so the specifics of business relations are most clearly demonstrated by contractual obligations. Conclusions: the provisions of the Civil Code of the Russian Federation, in addition to the general provisions on obligations, also contain provisions that are only applicable to obligations related to the implementation of business activities. Business obligations are specific in nature, and sometimes directly opposite to traditional obligations. As a result of the process of evolution, the digital economy has become one of the main engines of the growth of the global economic system. The widespread use of digital technologies increases competition in global markets and encourages leading industrial countries to implement appropriate economic policies and develop contractual relations.
\end{abstract}

Key words: obligations, contractual level, digitalization, economy, business activity, transaction, debtor.

Citation. Safarli N.E. oglu. Obligational Relations in the Midst of Digitalization of Business Activity: The Concept and Types. Legal Concept = Pravovaya paradigma, 2021, vol. 20, no. 3, pp. 143-148. (in Russian). DOI: https://doi.org/10.15688/lc.jvolsu.2021.3.21

УДК 34.347 .45

Дата поступления статьи: 25.04.2021

ББК 67.0

Дата принятия статьи: 10.06.2021

\section{ОБЯЗАТЕЛЬСТВЕННЫЕ ОТНОШЕНИЯ В УСЛОВИЯХ ЦИФРОВИЗАЦИИ ПРЕДПРИНИМАТЕЛЬСКОЙ ДЕЯТЕЛЬНОСТИ: ПОНЯТИЕ И ВИДЫ}

\author{
Низами Эльмар оглы Сафарли \\ Волгоградский государственный университет, г. Волгоград, Российская Федерация
}

\footnotetext{
Введение: гражданско-правовые обязательства являются одним из центральных институтов, входящих в систему гражданского права, который сегодня переживает новый этап осмысления, а также развития. Отечественная цивилистика достаточно отчетливо обозначила задачи, которые являются неотложными для теоретических, а также сравнительно-практических исследований, направленных на анализ проблем обязательств, которые вытекают из гражданско-правовых и предпринимательских договоров. Цель: проанализировать особенности регулирования рыночных отношений на договорном уровне в условиях цифровизации предпринимательской деятельности. Методы: в работе использованы методы системности, анализа и сравактивном внерении и
} 
закона. В качестве одного из них выступает договор, поэтому специфику предпринимательских отношений наиболее ярко демонстрируют именно договорные обязательства. Выводы: ГК РФ, помимо общих положений об обязательствах, также содержат те, которые применимы только к обязательствам, связанным с осуществлением предпринимательской деятельности. Предпринимательские обязательства специфичны по своей сути и иногда прямо противоположны традиционным обязательствам. В результате процесса эволюции цифровая экономика стала одним из главных двигателей роста мировой экономической системы. Широкое распространение цифровых технологий усиливает конкуренцию на глобальных рынках и стимулирует ведущие индустриальные страны к проведению соответствующей экономической политики и развитию договорных отношений.

Ключевые слова: обязательства, договорной уровень, цифровизация, экономика, предпринимательская деятельность, сделка, должник.

Цитирование. Сафарли Н. Э. оглы. Обязательственные отношения в условиях цифровизации предпринимательской деятельности: понятие и виды // Legal Concept = Правовая парадигма. - 2021. - T. 20, № 3. C. 143-148. - DOI: https://doi.org/10.15688/lc.jvolsu.2021.3.21

\section{Введение}

В соответствии со ст. 307 ГК РФ, закрепляющей понятие обязательства как правоотношение, в силу которого одно лицо (должник) обязано совершить в пользу другого лица (кредитора) определенное действие по передаче имущества, выполнению работы, оказанию услуги, внесению вклада в совместную деятельность, уплате денег и т. п. или же воздержаться от определенного действия, а кредитор наделен правом требования от должника исполнения его обязанности [3].

\section{Виды обязательств}

Существуют различные критерии классификации обязательств. Так, по основаниям возникновения они делятся на две группы [1, с. 21]:

- вытекающие из нормального гражданского оборота, возникающие из правомерных действий, в которых основание возникновения абсолютного большинства обязательств составляют сделки, к одному из наиболее распространенных видов которых относятся двусторонние сделки - договоры, а возникающие их них обязательства получили название договорных;

- обязательства, направленные на восстановление нарушенного гражданского права, получившие название деликтных, к основным из которых относятся обязательства из причинения вреда и неосновательного обогащения. Возникая в результате нарушения одним лицом имущественного положения дру- гого лица, данные обязательства имеют общую направленность: восстановление прежнего имущественного состояния потерпевшего.

Обязательства могут классифицироваться на возникающие из договора, то есть соглашения двух и более лиц и на обязательства, возникающие из положенных в их основу односторонних действий, которые получили название односторонних сделок. Примером обязательства из односторонних действий является публичное обещание награды, как это предусмотрено ст. 1055 ГК РФ [4].

Бывают обязательства солидарными и долевыми. По солидарному обязательству кредитор при множественности лиц на стороне должника имеет право предъявить требование как ко всем должникам, так и к любому из них. При этом любой из должников отвечает перед кредитором как в полном объеме, так и в части общего долга. При неполучении от одного из солидарных должников полного удовлетворения кредитор имеет право требования недополученного от солидарных должников.

При множественности лиц в долевых обязательствах на стороне кредитора и на стороне должника на основании ст. 321 ГК РФ каждый из кредиторов вправе требовать исполнения, а каждый из должников обязан исполнить обязательство в равной доле с другими, если иное не вытекает из закона, иных правовых актов или условий обязательства.

Обязательства можно классифицировать на возникающие из договора как соглашения двух и более лиц и из односторонних действий в их основе - односторонних сделок. Пример - 
публичное обещание награды согласно ст. 1055 ГК РФ.

Научная литература содержит достаточно много высказываний об особенностях обязательств, связанных с предпринимательской деятельностью их сторон $[8$, с. 103]:

- ст. 310 ГК РФ допускается односторонний отказ от исполнения обязательства и одностороннее изменение условий такого обязательства не только по общему правилу, когда это предусмотрено законом, но и в случаях, предусмотренных договором, если из закона или существа обязательства не вытекает иное;

- ст. 315 ГК РФ установлена возможность досрочного исполнения обязательств лишь в случаях, когда такое исполнение предусмотрено законом, иными правовыми актами, условиями обязательства либо вытекает из обычаев делового оборота или существа обязательства, тогда как по общему правилу должнику предоставлено право досрочного исполнения обязательства, кроме случаев, предусмотренных законом, иными правовыми актами или условиями обязательства, либо не вытекает из его существа;

- ст. 322 ГК РФ закреплены особенности ответственности и требования по такому обязательству - солидарной обязанности должников, как и требований нескольких кредиторов, если иное не предусмотрено законом, иными правовыми актами или условиями обязательства, тогда как по общему правилу солидарная ответственность (обязанность) или солидарное требование возникает, если такая солидарность установлена законом или предусмотрена договором;

- ст. 401 ГК РФ определена безвиновная ответственность лица, не исполнившего обязательства или исполнившего его ненадлежащим образом, тогда как общее правило требует наличия вины лица, не исполнившего обязательство либо исполнившего его ненадлежащим образом, кроме случаев, когда иные основания ответственности предусмотрены договором или законом.

Обязательства, связанные с осуществлением предпринимательской деятельности, возникают на основании заключения предпринимательского договора. На основе анализа гражданско-правовых норм может быть вы- делено несколько их групп, косвенно подразумевающих предпринимательский договор:

- нормы, указывающие на участников договорных обязательств как на субъектов предпринимательской деятельности. Это ст. 426 ГК РФ - публичный договор, ст. 825 ГК РФ - финансовый агент, ст. 1015 ГК РФ доверительный управляющий, ст. 1027 ГК РФ - договор коммерческой концессии;

- нормы, которые как на сторону обязательства указывают на лиц, осуществляющих предпринимательскую деятельность. Это ст. 506 - договор поставки, ст. 525 - основания поставки товаров для государственных и муниципальных нужд, ст. 535 - договор контрактации, ст. 907 - договор складского хранения;

- нормы, которыми цели использования передаваемого имущества определены как предпринимательские. Это ст. 665 - договор финансовой аренды.

Но подобная классификация норм с позиций определения особенностей предпринимательского договора представляется формальной. Так, ст. 426, 825, 1015, 1027 ГК РФ на принадлежность к субъектам предпринимательской деятельности лиц - участников договорных обязательств не указывают, а отмечают только участие в таких отношениях коммерческих организаций либо и коммерческих организаций, и индивидуальных предпринимателей.

Понятия «субъект предпринимательской деятельности», «коммерческая организация» и «индивидуальный предприниматель» не идентичны [5, с. 133].

Статьей 2 ГК РФ предпринимательская деятельность определена как самостоятельная, осуществляемая на свой риск деятельность, направленная на систематическое получение прибыли от пользования имуществом, продажи товаров, выполнения работ или оказания услуг лицами, в установленном законом порядке зарегистрированными в этом качестве [2, с. 96].

Статьей 23 ГК РФ закреплено право гражданина осуществлять предпринимательскую деятельность без образования юридического лица с момента его государственной регистрации в качестве индивидуального предпринимателя. Административным, налоговым 
и уголовным законодательством предусмотрены довольно серьезные последствия несоблюдения этого требования. При нарушении указанной нормы гражданин, осуществляющий предпринимательскую деятельность без образования юридического лица в отношении заключенных им при этом сделок, не может ссылаться на то, что он предпринимателем не является.

Несколько иная ситуация складывается в отношении юридических лиц - коммерческих и некоммерческих организаций. Коммерческие организации ст. 50 ГК РФ определены как юридические лица, в качестве основной цели своей деятельности, преследующие извлечение прибыли. К некоммерческим отнесены организации, извлечение прибыли основной целью своей деятельности не имеющие и между участниками ее не распределяющие, но в силу ст. 50 ГК РФ способные к осуществлению предпринимательской деятельности, поскольку это соответствует целям их создания и служит достижению этих целей.

Из этого следует, что некоммерческие организации также относятся к субъектам предпринимательской деятельности и это отмечается не только в учебной литературе [6, c. 47], но и в судебной практике: с одной стороны, особенности правового режима предпринимательской деятельности судами распространяются на отношения независимо от организационно-правовой формы участвующих в них лиц, а с другой - признают возможность заключения сделок, не относящихся к предпринимательской деятельности, коммерческими организациями.

По соотношению свободы и ответственности предпринимательские договоры подразделяются на три группы:

1) заключаемые между предпринимателями;

2) заключаемые между предпринимателями и потребителями;

3) заключаемые предпринимателями с публичными образованиями.

Свобода договора в наибольшей степени проявляется в двусторонних предпринимательских договорах, поскольку взаимная ответственность предпринимателей основана на правовом равенстве, изъятия из этого правила в большинстве случаев установлены к обя- зательствам предпринимателей перед потребителями, что подтверждает особую его защищенность как участника гражданского оборота $[7$, с. 136].

\section{Выводы}

Таким образом, положения ГК РФ, помимо общих положений об обязательствах, также содержат положения, которые применимы только к обязательствам, связанным с осуществлением предпринимательской деятельности. Целесообразно заметить, что предпринимательские обязательства специфичны по своей сути, а также иногда прямо противоположны традиционным обязательствам.

Как экономическое явление, предпринимательство объективно требует правового регулирования, поскольку его отсутствие неизбежно проявляется в таких отрицательных последствиях, как неравномерность распределения благ, безработица, монополизация экономики. Правовое регулирование обеспечивает реализацию равенства как одного из важнейших принципов гражданского права: установив для предпринимателей дополнительные требования, государство уравняло их с другими участниками оборота. Этим же продиктована необходимость в активном внедрении и применении правовых средств как инициативных действий, основанных на дозволении закона. В качестве одного из них выступает договор, поэтому специфику предпринимательских отношений наиболее ярко демонстрируют именно договорные обязательства.

Таким образом, следует заключить, что цифровая экономика стала итогом глубокого проникновения мобильного интернета, облачных вычислений, больших данных и других технологий нового поколения на каждый уровень социума. В результате процесса эволюции цифровая экономика стала одним из главных двигателей роста мировой экономической системы. Широкое распространение цифровых технологий усиливает конкуренцию на глобальных рынках и стимулирует ведущие индустриальные страны к проведению соответствующей экономической политики и увеличению инвестиций в научные исследования.

К трендам цифровизации экономики в рамках технического подхода относятся об- 
лачные вычисления, интернет вещей, искусственный интеллект, робототехника, блокчейн. В рамках экономического подхода тренды цифровизации экономики связаны с модернизацией реальных секторов экономики, цифровым развитием предпринимательской среды, развитием инноваций, а также снижением энергопотребления и выбросов в атмосферу.

Развитие цифровой экономики является основой экономической независимости и обеспечивает конкурентоспособность страны на рынке. В связи с этим правительства различных стран (Евразийский экономический союз, Соединенные Штаты Америки, Китай и Россия) разрабатывают и внедряют государственные программы по развитию цифровой экономики и дальнейшей модернизации производств. Государственные программы развития цифровой экономики направлены на эффективное продвижение новых технологий в те области, которые обладают конкурентоспособным потенциалом и дают возможность структурной перестройки экономики.

\section{СПИСОК ЛИТЕРАТУРЫ}

1. Белов, В. А. Вещное и обязательственное право в структуре арендных отношений (имущественного найма). Правомочия арендатора / В. А. Белов // Научные труды РАЮН. Вып. 14. В 2 т. Т. 2 / под ред. В. В. Гриб. - М. : Юрист, 2014. - С. 18-24.

2. Волос, А. А. Отличительные признаки принципов обязательственного права / А. А. Волос // Вестник Воронежского государственного университета. - Воронеж : Изд-во Воронеж. ун-та, 2014. № 2 (17). - С. 91-96.

3. Гражданский кодекс Российской Федерации (часть первая) от 30.11.1994 № 51-Ф3 (ред. от 09.03.2021) // Собрание законодательства РФ. 1994. - № 32. -Ст. 3301.

4. Гражданский кодекс Российской Федерации (часть вторая) от 26.01.1996 № 14-ФЗ (ред. от 09.03.2021) // Собрание законодательства РФ. 1996. - № 5. - Ст. 410.

5. Матыцин, Д. Е. Обеспечение исполнения государственных и муниципальных контрактов: банковские гарантии и цифровые технологии / Д. Е. Матыцин, И. В. Балтутите // Евразийский юридический журнал. - 2020. - № 11 (150). - С. 133-136.

6. Матыцин, Д. Е. Опыт судебного правоприменения по корпоративным спорам, связан- ным с истребованием акций из незаконного чужого владения и цифровые технологии / Д. Е. Матыцин // Законы России: опыт, анализ, практика. 2020. - № 10. - C. 43-47.

7. Матыцин, Д. Е. Цифровые технологии реализации гражданско-правовых сделок: договор репо на инвестиционные активы рынка ценных бумаг / Д. Е. Матыцин // Право и практика. $-2020 .-$ №2. - С. 136-140.

8. Рузанова, В. Д. Видовые особенности гражданско-правовых предпринимательских обязательств и обязательственных прав / В. Д. Рузанова // Субъективные права в сфере обязательств: проблемы юридической сущности и систематизации : сб. науч. ст. / под ред. С. В. Мартышкин, Ю. С. Поваров. - Самара : Самарский университет. - 2010. C. $88-104$.

\section{REFERENCES}

1. Belov V.A. Veshchnoe i obyazatel'stvennoe pravo $v$ strukture arendnyh otnoshenij (imushchestvennogo najma). Pravomochiya arendatora [Real and Binding Law in the Structure of Rental Relations (Property Hiring). The Rights of the Tenant]. Nauchnye trudy RAYUN. Vyp. 14. V 2 t. T. 2 [Scientific Works of RAYUN. No. 14. In 2 vol., vol. 2]. Moscow, Yurist Publ., 2014, pp. 18-24.

2. Volos A.A. Otlichitel'nye priznaki principov obyazatel'stvennogo prava [Distinctive Features of the Principles of the Law of Obligations]. Vestnik Voronezhskogo gosudarstvennogo universiteta [Bulletin of the Voronezh State University]. Voronezh, Izd-vo Voronezh. un-ta, 2014, no. 2 (17), pp. 91-96.

3. Grazhdanskij kodeks Rossijskoj Federacii (chast' pervaya) ot 30.11.1994 № 51-FZ (red. ot 09.03.2021) [Civil Code of the Russian Federation (Part One)]. Sobranie zakonodatel'stva RF [Collection of the Legislation of the Russian Federation], 1994, no. 32, art. 3301 .

4. Grazhdanskij kodeks Rossijskoj Federacii (chast' vtoraya) ot 26.01.1996 № 14-FZ (red. ot 09.03.2021) [The Civil Code of the Russian Federation (Part Two)]. Sobranie zakonodatel'stva RF [Collection of the Legislation of the Russian Federation], 1996, no. 5 , art. 410 .

5. Matycin D.E., Baltutite I.V. Obespechenie ispolneniya gosudarstvennyh i municipal'nyh kontraktov: bankovskie garantii i cifrovye tekhnologii [Ensuring the Execution of State and Municipal Contracts: Bank Guarantees and Digital Technologies]. Evrazijskij yuridicheskij zhurnal [Eurasian Legal Journal], 2020, no. 11 (150), pp. 133-136.

6. Matycin D.E. Opyt sudebnogo pravoprimeneniya po korporativnym sporam, svyazannym $\mathrm{s}$ 
istrebovaniem akcij iz nezakonnogo chuzhogo vladeniya i cifrovye tekhnologii [Experience of Judicial Law Enforcement in Corporate Disputes Related to the Recovery of Shares from Illegal Alien Ownership and Digital Technologies]. Zakony Rossii: opyt, analiz, praktika [Laws of Russia: Experience, Analysis, Practice], 2020, no. 10, pp. 43-47.

7. Matycin D.E. Cifrovye tekhnologii realizacii grazhdansko-pravovyh sdelok: dogovor repo na investicionnye aktivy rynka cennyh bumag [Digital Technologies for the Implementation of Civil Law Transactions: A Repo Agreement for Investment
Assets of the Securities Market]. Pravo i praktika [Law and Practice], 2020, no. 2, pp. 136-140.

8. Ruzanova V.D. Vidovye osobennosti grazhdansko-pravovyh predprinimatel'skih obyazatel'stv i obyazatel'stvennyh prav [Specific Features of Civil Legal Business Obligations and Contractual Rights]. Subyektivnye prava $v$ sfere obyazatel'stv: problemy yuridicheskoj sushchnosti $i$ sistematizacii: sbornik nauchnyh statej [Rights in the Sphere of Obligations: Problems of Legal Entities and Systematization: Collected Articles]. Samara, Samarskij universitet, 2010, pp. 88-104.

\section{Information About the Author}

Nizami Elmar oglu Safarli, Postgraduate Student, Department of Civil and Private International Law, Volgograd State University, Prosp. Universitetsky, 100, 400062 Volgograd, Russian Federation, Nizami1994@gmail.com, https://orcid.org/0000-0002-4568-5774

\section{Информация об авторе}

Низами Эльмар оглы Сафарли, аспирант кафедры гражданского и международного частного права, Волгоградский государственный университет, просп. Университетский, 100, 400062 г. Волгоград, Российская Федерация, Nizami1994@gmail.com, https:/orcid.org/0000-0002-4568-5774 